Article

\title{
Design of PI Controllers for Irrigation Canals based on Linear Matrix Inequalities
}

\author{
Teresa Arauz ${ }^{1}$, José M. Maestre ${ }^{1}$, Xin Tian 2,3,*(D), and Guanghua Guan ${ }^{4}$ \\ 1 Department of Systems and Automation Engineering, University of Seville, 41092 Seville, Spain; \\ teresa.arauz.pison@gmail.com (T.A.); pepemaestre@us.es (J.M.M.) \\ 2 Department of Water Management, Delft University of Technology, 2611 CD Delft, The Netherlands \\ 3 KWR Water Research Institute, Groningenhaven 7, 3433 PE Nieuwegein, The Netherlands \\ 4 State Key Laboratory of Water Resources and Hydropower Engineering Science, Wuhan University, \\ Wuhan 430072, China; GGH@whu.edu.cn \\ * Correspondence: x.tian@tudelft.nl
}

Received: 4 February 2020; Accepted: 12 March 2020; Published: 18 March 2020

\begin{abstract}
A new Proportional-Integral (PI) tuning method based on Linear Matrix Inequalities (LMIs) is presented. In particular, an LMI-based optimal control problem is solved to obtain a sparse feedback that provides the PI tuning. The ASCE Test Canal 1 is used as a case study. Using a linearised model of the canal, different tunings for the design of the PI controller are developed and tested using the software Sobek. Furthermore, the proposed method is also compared with other tunings proposed for the same canal available in the literature. Our results show that the proposed method reduces by half the maximum errors with respect to other assessed alternatives and minimizes undesired mutual interactions between canal pools. Also, our method improves the optimality degree of the PI tuning by $30 \%$. Therefore, it is concluded that the LMI based PI controllers lead to satisfactory performance in regulating water levels and canal flows/structure outflows, outperforming other tested alternatives, thus becoming a useful tool for irrigation canal control.
\end{abstract}

Keywords: decentralized control; controller constraints and structure; multivariable systems; irrigation canals; PI design

\section{Introduction}

At the beginning of this century, 2.7 million $\mathrm{km}^{2}$ of land was irrigated worldwide, and the water consumed represented nearly $85 \%$ of the total amount of water used for human consumption [1]. Also, the high number of water withdrawals (roughly $3900 \mathrm{~km}^{3} /$ year represents $10 \%$ of total global resources [2]). For these reasons, the management of irrigation canals is gaining relevance.

Since the USA and Asia have the majority of irrigation areas [3], many studies are focused on those regions searching for improvements in this activity. Some experts warn about the disappointing canal performance in South and Southeast Asia [4]. In particular, canal irrigation management becomes even more complicated in arid and semi-arid areas, e.g., in some water districts in Iran, where surface water is used in conjunction with groundwater for irrigation, thus causing groundwater overexploitation. To reduce the amount of irrigation water used by improving water distribution and delivery, some operational model alternatives are studied and applied in [5].

In response, researchers have been working to develop more efficient control algorithms. These canal control algorithms are focused on regulating irrigation canals and different features can classify them depending on whether they are focused on considered variables, the control logic or the design technique [6]. Some examples of main design techniques commonly used are the heuristic, three-position, PID, optimal control and predictive control among others [6]. Considering 
the heuristic control, Canal Automation for Rapid Demand Deliveries (CARDD) [7] is a well-known control algorithm in the irrigation canal sector. This strategy consists of independent controllers that control "a target depth at the downstream end of each pool" [8]. BIVAL system [9] is an example of a three-position controller which is based on a simple linear equation and measures downstream and upstream levels to adapt the upstream movement gate to the downstream demand. Generally, PID algorithms are the most employed control strategies as well as in water canal management. Mainly, what a PID control system does is to compare "the measured water depth and target value in the canal reach and calculates the gate opening accordingly" [10]. In this article, two PID control systems are studied, the downstream and upstream control systems, concluding that the first system performance is better than the second one.

Model Predictive Control (MPC) strategy is another control algorithm also applied in irrigation canals, although it is harder to implement than the previous solutions. This approach consists of " $a$ model-based control strategy in which prediction models are used in optimization to determine optimal control inputs over a given horizon" [11]. One example is the one presented in [11], where, in a distributed control scheme of an irrigation canal, local MPCs are defined and the overall system performance is improved thanks to the communication between local controllers. Another case is the decentralized model predictive control applied in [12]. Its performance is compared with the centralized one, emphasizing the obtained advantages of the decentralized MPC controller. Many other examples can be found in the literature [13-18].

Some studies have also been carried out to compare some control algorithms performance applied to irrigation canals [19], e.g., in [20], three downstream control algorithms were tested: a standard PI control logic, the PI control logic with hydraulic decouplers, and the heuristic CARDD control logic. The conclusion was that the PI controller performance is enhanced by adding the decouplers, and even better than the CARDD's under the conditions imposed in the tests.

Considering all the control algorithm possibilities, this study is based on the PI controller. It aims to develop a new method to tune PI controllers for irrigation water canals. Nowadays, it is difficult to tune these parameters, mainly in distributed systems [21,22], and thus many methods for PI engineering tuning have been provided, based on various control theories [23-25]. For example in [26], the Auto-Tune Variation method is presented and applied to the Gignac Canal (France). In [22], the velocity form of the PI is used for tuning and tested in the Highline Canal in Grand Valley (USA). In [27], fuzzy control is combined with PID control to enable a real-time self-tuning method for the controller parameters. In [28], a PI controller is designed following a model-based methodology and is applied to an experimental canal located in Portugal. In [29], PI parameters are optimized iteratively using the simplex method. This approach is also used in [30], where multiple simulations of unsteady flow are carried out to search the optimal values of PI gains for a case study located in Spain, and in [31], where a given set of inflow canal perturbations is considered in the optimization. In [32], multiple-model optimization is used to robustify local PI controllers applied in series with filters in the West main canal of the Dez irrigation system (Iran). In [21], a distant downstream PI feedback control with decouplers is designed and tuned using the canal parameters of its case study. In [33], the PI controller parameters are analytically obtained as a function of the physical parameters of some pools in the ASCE Test Cases. A similar approach is followed in [34], where PI parameters are obtained from system parameters by minimizing the absolute error integral after a step setpoint change.

Similarly, the Linear Matrix Inequalities (LMIs) approach is used in this study to design PI controllers. Since formulating a control problem using LMI requires a lower number of elementary technical results [35], many works follow this approach. For example, in [36] LMIs are used for a PI that changes with operation points. Instead, our approach aims at designing the PI controllers as optimal control problems. Indeed, in [37] this approach is used for irrigation canals but it leads to a non-convex problem formulation that is solved numerically and without any type of guarantee regarding the solution found. 
Likewise, to design a PI controller using the LMI approach, certain elements of the control law are identified with the tuning parameters of a P or PI controller. By imposing some additional constraints in the controller design, the rest of the elements in the feedback matrix become zero. These types of constraints can be easily introduced using LMI controller design methods which has also been studied previously in other works [38-40]. In addition, there are also related articles in the literature which can be applied to other fields, such as the LMI design method to impose communication constraints related to the control network topology proposed in [41,42]. Likewise, a similar approach for the design of column sparse feedback controllers for linear systems is proposed via LMI in [43].

With the goal of studying the performance of the algorithm developed, one of the Test Canals provided by ASCE is selected [44]. Since the publication of [44], these test canals have been used several times in the literature, e.g., the ASCE Test Canal 1 is used in [45] and [37]. This canal is based on the WM Canal of the Maricopa Stanfield Irrigation and Drainage District (central Arizona) [37]. It is characterized as a steep canal with very little storage and with eight pools of varying length separated by a vertical sluice gate at the end of each one $[44,46]$. Here, we use a linear model of this canal to implement the controller and tune the PI parameters.

As has been shown in the literature review, tuning PI controllers in this context can be challenging. Several strategies have been proposed: some methods link the controller parameters with those of the canal; other alternatives focus on controller optimization, e.g., by using the simplex method. In this article, these two approaches are combined and the PI tuning problem is recast as a linear feedback design that is efficiently calculated using LMIs. The resulting framework is very versatile and can be easily extended to consider constraints, uncertainty, and even more sophisticated controllers such as PIs with decouplers. In a nutshell, this research has the following objectives:

- To provide a novel design method for PI controllers in irrigation canals.

- To bring the benefits of LMI based design to irrigation canals, thus providing a design framework for linear controllers that can deal with issues as uncertainties in model parameters in a natural way.

- To exploit subsystem synergies by using a centralized design to avoid undesired mutual interaction.

- To make controller tuning closer to actual canal performance.

- To validate and assess our results using a digital twin of ASCE Test Canal 1, which is implemented in a realistic state of the art software.

The rest of the paper is organized as follows. First, the system equations are detailed and an introduction about how design constraints are considered is given. Then, LMI equations are deduced, and the controller design method is presented. The next section introduces the ASCE Test Canal 1 characteristics and properties, which is the model used for tests. Then simulation settings are detailed, including the linear canal model on which the controller is designed. After that, the different methods developed and the characteristics of simulations are presented. Next, the performance indicators that are calculated and used for comparison between methods are introduced. Then, the simulation results obtained from Sobek software are shown as well as correlating comments. Finally, some conclusions are put forward in the last section.

\section{Materials and Methods}

\subsection{Problem Setting}

An irrigation canal system is often comprised of a series of pools and gates which regulate the water discharge flowing from upstream to downstream. The flows and water level changes in open canals can be accurately modeled by the Saint-Venant equations. However, due to their numerical complexity, simplified models are usually derived from them. Here, a linear canal model is considered for the controller design. 
From a mathematical viewpoint, we assume that the overall system is composed of a set of $\mathcal{N}=\{1,2, \ldots, N\}$ discrete linear time-invariant subsystems. So the dynamics of subsystem $i \in \mathcal{N}$ are given by

$$
x_{i}(k+1)=A_{i i} x_{i}(k)+B_{i i} u_{i}(k)+d_{i}(k),
$$

where $x_{i} \in \mathbb{R}^{q_{i}}$ and $u_{i} \in \mathbb{R}^{r_{i}}$ with $i \in N$, are the states and inputs of each subsystem, respectively, which in this context are typically water level deviations from a given reference level and possibly delayed flows. The matrices $A_{i i}$ and $B_{i i}$ are respectively the state-transition and the input-to-state matrices of the linear model. The number of states and controls of the $i$-th subsystem are respectively denoted as $q_{i}$ and $r_{i}$, and in the overall system $q$ and $r$.

The final term of Equation (1), $d_{i}$, represents the disturbances between the subsystems defined as the influence of the neighbors' states and inputs in the update of $x_{i}$, which becomes

$$
d_{i}(k)=\sum_{j \neq i} A_{i j} x_{j}(k)+\sum_{j \neq i} B_{i j} u_{j}(k),
$$

where matrices $A_{i j}$ and $B_{i j}$ map respectively the state and inputs a subsystem $j \in \mathcal{N}$ into the state of subsystem $i$ and have the proper dimensions. External disturbances are omitted for simplicity here but without loss of generality regarding the proposed method.

Each subsystem described by (1) has its own goal: to minimize a stage cost defined for convenience as

$$
\ell_{i}(k)=x_{i}^{T}(k) Q_{i} x_{i}(k)+u_{i}^{T}(k) R_{i} u_{i}(k),
$$

where $Q_{i} \in \mathbb{R}^{q_{i} \times q_{i}}$ and $R_{i} \in \mathbb{R}^{r_{i} \times r_{i}}$ are respectively positive semi-definite and definite constant weighting matrices. Physically, the cost penalizes the absolute water deviations and changes in gate flows with respect to the operation point, which for simplicity is assumed to be zero.

Finally, the overall system dynamics and cost function can be obtained aggregating all the subsystems ones described by (1)-(3):

$$
\begin{gathered}
x_{\mathcal{N}}(k+1)=A_{\mathcal{N}} x_{\mathcal{N}}(k)+B_{\mathcal{N}} u_{\mathcal{N}}(k), \\
\ell_{\mathcal{N}}(k)=x_{\mathcal{N}}^{T}(k) Q_{\mathcal{N}} x_{\mathcal{N}}(k)+u_{\mathcal{N}}^{T}(k) R_{\mathcal{N}} u_{\mathcal{N}}(k),
\end{gathered}
$$

where the subscript $\mathcal{N}$ places an emphasis on that all system vectors and matrices come from the aggregation of local subsystems, i.e., $x_{\mathcal{N}}=\left[x_{i}\right]_{i \in \mathcal{N}}, u_{\mathcal{N}}=\left[u_{i}\right]_{i \in \mathcal{N}}, A_{\mathcal{N}}=\left[A_{i j}\right]_{i, j \in \mathcal{N}}$, and $B_{\mathcal{N}}=$ $\left[B_{i j}\right]_{i, j \in \mathcal{N}} ; Q_{\mathcal{N}}=\operatorname{diag}\left(Q_{i}\right)_{i \in \mathcal{N}}$ and $R_{\mathcal{N}}=\operatorname{diag}\left(R_{i}\right)_{i \in \mathcal{N}}$. Note that the result for the update of the overall system state is just influenced by the actual state and input, missing the term of disturbances (due to the mutual interactions between pairs of subsystems).

\section{The Linear Canal Model}

In this study, a linear canal model is considered for the controller design and tune process, particularly, the Integrator-Delay (ID) model $[47,48]$. This model has been chosen due to its simplicity and convenience, but any other linear model could have been selected instead. The ID model is a simple discrete linear model for canal pool response given by

$$
\Delta h(k)=\frac{T_{s}}{A_{s}}\left[q_{u}\left(k-\tau_{R}\right)-q_{d}(k)\right],
$$

where $\Delta h(k)$ represents the water level change; $k$, the integer time step; $T_{s}$, the duration of the time step; $A_{s}$, the backwater surface area; $q_{u}$ and $q_{d}(k)$, the upstream and the downstream flow rates respectively; and $\tau_{R}$ the closest integer representing the delay time $(\tau / T s)$. Note that for this model, a canal pool is formed by a first portion of normal depth and the remaining portion under backwater. In essence, this model relates water level changes at the downstream end of the pool to flow changes through gates at the upstream and downstream end of the pool, and the delay time is the responsible of that 
difference. One of the advantages of this model is that gate control schemes are expressed in the form of flow-rate controls, thus avoiding the complexity of including gate hydraulics in the controller design.

The global system dynamics relates all water-level measurements (inputs) with all check structure flow adjustments (outputs). Therefore, actual physical states have to be included in the state vector $x(k)$ of the designed control scheme. In tests, the system is considered to start in the steady-state, so all the system variables are referred to that state. The matrices for the linear canal model are defined from the properties of the ASCE Test Canal 1 [44], which will be introduced later.

Furthermore, some extra elements have to be included in the state vector $x(k)$ for the sake of the feedback controller $K$. In particular, the integral error values are incorporated since the controller has to consider both proportional and integral constants of a PI controller. Also, recall that additional terms for lagged flow measurements are added to account for the effect of the delay time for water to travel across canals in a discrete-time controller. For example, a three-pool canal system considering the aforementioned extra elements could have a state vector $x(k)$ as follows [49]:

$$
x(k)=\left[\begin{array}{c}
\Delta e_{1}(k) \\
\Delta u_{1}(k-2) \\
\Delta u_{1}(k-1) \\
\Delta e_{2}(k) \\
\Delta u_{2}(k-1) \\
\Delta e_{3}(k) \\
e_{1}(k-1) \\
e_{2}(k-1) \\
e_{3}(k-1)
\end{array}\right]
$$

where $\Delta e_{i}(k)$ for $i=1, \ldots, 3$ are changes in water-level error at time step $k$ in pools 1,2 and 3 respectively; $e_{i}(k-1)$ for $i=1, \ldots, 3$ are water-level error at time step $k-1$ in pools 1,2 and 3 respectively; and $\Delta u_{i}(k-1)$ and $\Delta u_{i}(k-2)$ for $i=1,2$ are control actions at prior time $k-1$ and $k-2$ in pools 1 and 2 respectively. Note that the added elements in the gain matrix corresponding to the extra lagged flow measurements will be forced to be zero due to they can not be controlled by the designed PI controller.

\subsection{Controller Design Procedure}

As mentioned in the previous section, the main goal of the overall system defined by (4) is to minimize the stage cost function (5) as water levels are steered towards the operation point. To this end, a sparse linear feedback controller will be designed, i.e., not all the states can be used to calculate the control actions. For example, the error in the first reach is not used to calculate the actions of the last one. Therefore, there is a mapping from system states to control actions that must be considered in the design to obtain the desired sparsity pattern in the feedback controller, thus implementing constraints in the information flows.

The mapping, denoted hereafter as $\Lambda$, connects the set of state variables, $\mathcal{X}$, and $\mathcal{U}$, which is the set control actions, i.e., $\Lambda: \mathcal{X} \rightarrow \mathcal{U}$. This mapping is clearly observed in the feedback matrix $K$, which sets that control action $u_{i}$ can receive information from state $x_{j}$ only if $K_{i, j} \neq 0$. Superscripts will be added in the control law to stress this fact: $u_{\mathcal{N}}=K^{\Lambda} x_{\mathcal{N}}$, with $\Lambda \in \mathcal{M}$, where $\mathcal{M}$ is the set of all possible information mappings.

This way, the resulting controller receives actual physical states through the state vector $x_{\mathcal{N}}(k)$ (water-level errors with respect their target levels) to generate structure flow adjustments. Moreover, since the gain matrix $K^{\Lambda}$ has to include both proportional and integral constants of a PI controller, not only error values have to be considered, but also the integral error values. Therefore, the state vector $x_{\mathcal{N}}(k)$ is extended with the water level integral errors of all states. Finally, the system is considered to 
be initially in the steady-state, so all the system variables are referred to this point, which becomes the origin for the linear model (4).

To clarify this concept, consider a system with four control actions and four state variables. Note that full state information leads to a feedback controller with the following structure

$$
K^{\Lambda_{\mathrm{LQR}}}=\left[\begin{array}{llll}
K_{11} & K_{12} & K_{13} & K_{14} \\
K_{21} & K_{22} & K_{23} & K_{24} \\
K_{31} & K_{32} & K_{33} & K_{34} \\
K_{41} & K_{42} & K_{43} & K_{44}
\end{array}\right] .
$$

Note that this is the case of the well-known linear quadratic regulator (LQR). Now, consider an alternative mapping $\Lambda_{\mathrm{ex}}$ where some information flows are disabled, e.g.,

$$
K^{\Lambda_{\mathrm{ex}}}=\left[\begin{array}{cccc}
K_{11} & K_{12} & K_{13} & 0 \\
K_{21} & K_{22} & 0 & K_{24} \\
K_{31} & 0 & K_{33} & 0 \\
0 & K_{42} & 0 & K_{44}
\end{array}\right] .
$$

Clearly, $K^{\Lambda_{\mathrm{ex}}}$ has fewer degrees of freedom to design the controller, but it may still be possible to find a controller with such structure. In the next section, we provide a method to design linear feedbacks with this type of constraints, which allows us calculating PI controllers for the system.

\subsubsection{Lmi Based Controller Design}

Definition: Given the matrix variables $X_{1}, X_{2}, \ldots, X_{m}$, the matrix function

$$
H\left(X_{1}, X_{2}, \ldots, X_{m}\right)>0
$$

is said to be a linear matrix inequality on the decision variables $X_{1}, X_{2}, \ldots, X_{m}$ if the following two conditions hold:

1. $H(\cdot)$ is a symmetric matrix for every $X_{1}, X_{2}, \ldots, X m$ and

2. the dependence of the matrix function $H(\cdot)$ with respect to all variable decision $X_{1}, X_{2}, \ldots, X m$ is affine.

Once a control problem has been formulated in LMI form, a feasible solution to the problem can be obtained very quickly using specialized optimization packages, as Matlab's LMI Control Toolbox [50].

The overall system dynamic has been already defined as (4). In order to guarantee the system stability, a Lyapunov function must be calculated so that the energy of the system decreases in each step, i.e., $\left(x^{+}\right)^{T} P x^{+}<x^{T} P x$ (to simplify notation $x^{+}=x(k+1)$ ). Also, in order to make $x^{T} P x$ a bound on the cost-to-go of the system this constrain is made more restrictive: the system is said to be stable if there is a matrix $P=P^{T}>0$ such that $\left(x^{+}\right)^{T} P x^{+}+x^{T} Q x+u^{T} R u<x^{T} P x$, which is equivalent to

$$
\left\{\begin{array}{r}
P>0 \\
P-(A+B K)^{T} P(A+B K)-Q-K^{T} R K>0 .
\end{array}\right.
$$

Next Schur's complement is applied to (8) to obtain

$$
\left[\begin{array}{cc}
P-Q-K^{T} R K & (A+B K)^{T} \\
A+B K & P^{-1}
\end{array}\right]>0
$$


At this point, the obtained matrix inequality is not linear because it contains terms on $P$ and $P^{-1}$ simultaneously, and also bilinear terms on $P$ and $K$. Thus, (9) is pre-multiplied and post-multiplied by the positive matrix $\left[P^{-1} 0 ; 0 I\right]$, obtaining

$$
\left[\begin{array}{cc}
P^{-1}-P^{-1} Q P^{-1}-P^{-1} K^{T} R K P^{-1} & P^{-1}(A+B K)^{T} \\
(A+B K) P^{-1} & P^{-1}
\end{array}\right]>0 .
$$

Then, performing the variable changes $W=P^{-1}$ and $Y=K P^{-1}$, the LMI problem is now expressed on the decision variables $W$ and $Y$ :

$$
\left[\begin{array}{cc}
W-W Q W-Y^{T} R Y & W A^{T}+Y^{T} B^{T} \\
A W+B Y & W
\end{array}\right]>0
$$

The first term of (11) is desired to be just $W$, so the other two elements depending on $Q$ and $R$ have to be moved. First, the $Q$ element is decomposed as

$$
\left[\begin{array}{cc}
W-Y^{T} R Y & W A^{T}+Y^{T} B^{T} \\
A W+B Y & W
\end{array}\right]-\left[\begin{array}{c}
W Q^{1 / 2} \\
0
\end{array}\right] I\left[\begin{array}{ll}
Q^{1 / 2} W & 0
\end{array}\right]>0
$$

If Schur's complement is applied:

$$
\left[\begin{array}{ccc}
W-Y^{T} R Y & W A^{T}+Y^{T} B^{T} & W Q^{1 / 2} \\
A W+B Y & W & 0 \\
Q^{1 / 2} W & 0 & I
\end{array}\right]>0
$$

Finally, doing the same but for the $Q$ element, the LMI problem formulation is achieved:

$$
\left[\begin{array}{cccc}
W & W A^{T}+Y^{T} B^{T} & W Q^{1 / 2} & Y^{T} R^{1 / 2} \\
A W+B Y & W & 0 & 0 \\
Q^{1 / 2} W & 0 & I & 0 \\
R^{1 / 2} Y & 0 & 0 & I
\end{array}\right]>0
$$

The next step is to obtain $W$ and $Y$ solving the previous LMI expression (14), but including some additional constraints to allow to introduce the zero elements in the feedback matrix. The first constrain is that matrix $W=W^{T}=\operatorname{diag}\left(W_{i}\right)_{i \in \mathcal{N}}$, where $W_{i} \in \mathbb{R}^{q_{i} \times q_{i}}$; and the second, $Y \in \mathbb{R}^{r \times q}$ with $Y_{\Lambda, i j}=Y_{i j}$ if the information flow from $x_{j}$ to calculate $u_{i}$ is allowed according to the specific mapping $\Lambda$, i.e., if $\left\{x_{j}, u_{i}\right\} \in \Lambda$, and $Y_{\Lambda, i j}=0$ otherwise.

Finally, the feedback matrix $K$ is obtained by reversing the variable change $K=Y W^{-1}$, which is a stabilizing control law where $K_{i j}^{\Lambda}=0$ if $Y_{\Lambda, i j}=0$. Note that matrix $P$ of the Lyapunov function is also obtained by undoing the variable change $P=W^{-1}$.

Therefore, to design the controller, we solve

$$
\max \operatorname{tr}(W)
$$

subject to (14) for the specific mapping $\Lambda$. Then it is enough to take $K^{\Lambda}=Y_{\Lambda} W^{-1}$. Note that the maximization of the trace of $W$ is an indirect manner of minimizing that of $P=W^{-1}$, hence minimizing the cost-to-go of the closed-loop system.

\subsubsection{Tuning}

The proposed controller is designed to minimize a cost that depends on the weighting matrices $Q$ and $R$. Therefore, diverse performances can be achieved just by tuning these weighting matrices. For convenience, $R$ was taken as the unit matrix and different controllers were designed by tuning 
the diagonal values of $Q$ corresponding to water level errors and their integrals, with higher weight assigned to the former. In particular, three tuning rules were considered for matrix $Q$ :

1. Penalties set by trial and error.

2. Penalties proportional to the pool length of each section.

3. Penalties proportional to the backwater surface area of each canal section.

\subsection{Other Methods}

Furthermore, the methods presented in [51] are also considered to assess the three proposed controllers. These methods consist of a set of four proportional-integral filtered (PIF) controllers. The main reason for choosing them is their similarity with this study: they are also based on different ways of tuning PI controllers for the automatic control of water levels upstream from canal gates; they are also tested in the ASCE Test Canal 1; and they are based on the same ID canal model. Moreover, their proportional and integral coefficients are given, making the comparison straight forward.

The four different tuning methods exposed are all based on a PIF controller for each pool determined independently with the resonance peak height based on the canal pool celerity, but each of them includes a different additional element [51]:

- Method 1: the resonance frequency based on the canal pool celerity.

- Method 2: the resonance frequency based on the canal pool celerity and integral constants adjusted based on downstream resonance.

- Method 3: the resonance frequency determined based on the maximum cross-over frequency.

- Method 4: the resonance frequency determined based on the maximum cross-over frequency and integral constants adjusted based on downstream resonance.

\subsection{Simulations}

Simulations were run in Sobek [52], which solves numerically the Saint Venant equations to calculate the unsteady flow in open channels.

\subsubsection{Case Study}

The ASCE Test Canal 1, a standardized irrigation canal model to check the suitability of control algorithms, is the scenario selected for testing the proposed algorithm.

The most relevant characteristics of the ASCE Test Canal 1 are summarized in Table 1, and a simplified canal scheme is shown in Figure 1 (further details are available in $[44,46,53]$.

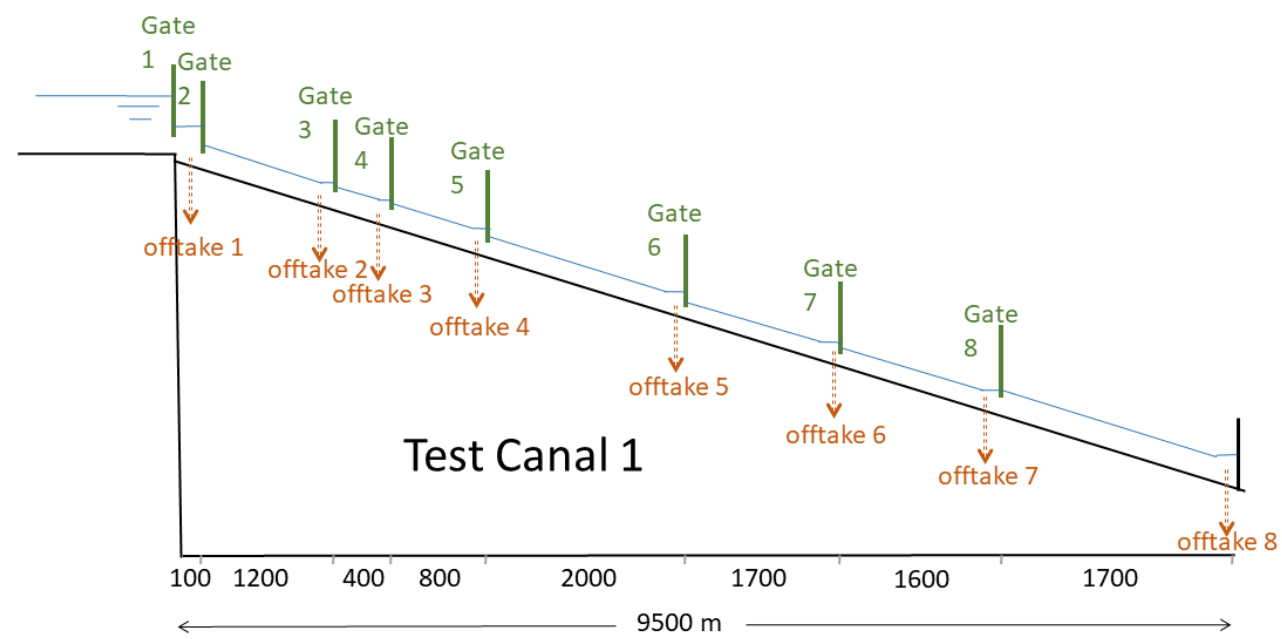

Figure 1. Profile of the ASCE Test Canal 1 taken from. 
Table 1. Properties and characteristics of the ASCE Test Canal 1.

\begin{tabular}{ccccc}
\hline \multicolumn{5}{c}{ ASCE Test Canal 1 } \\
\hline $\begin{array}{c}\text { Bottom } \\
\begin{array}{c}\text { Slope } \\
(\mathbf{m} / \mathbf{m})\end{array}\end{array}$ & $\begin{array}{c}\text { Manning's } \\
\mathbf{n}(-)\end{array}$ & $\begin{array}{c}\text { Side } \\
\text { Slopes } \\
(\mathbf{m} / \mathbf{m})\end{array}$ & $\begin{array}{c}\text { Drop at } \\
\text { Each } \\
\text { Gate }(\mathbf{m})\end{array}$ & $\begin{array}{c}y_{\text {target }} / \\
\mathbf{y}_{\text {normal }} \\
(\mathbf{m} / \mathbf{m})\end{array}$ \\
\hline 0.002 & 0.014 & 1.5 & 1.0 & 1.45 \\
\hline $\begin{array}{c}\text { Pool } \\
\text { Number }\end{array}$ & $\begin{array}{c}\text { Pool } \\
\text { Length } \\
(\mathbf{m})\end{array}$ & $\begin{array}{c}\text { Upstream } \\
\text { Elevation } \\
(\mathbf{m})\end{array}$ & $\begin{array}{c}\text { Downstream } \\
\text { Elevation } \\
(\mathbf{m})\end{array}$ & $\begin{array}{c}\text { Target } \\
\text { Level } \\
(\mathbf{m})\end{array}$ \\
\hline 1 & 100 & 415.6 & 415.3 & 0.9 \\
\hline 2 & 1200 & 408.0 & 405.6 & 0.9 \\
\hline 3 & 400 & 403.4 & 402.6 & 0.8 \\
\hline 4 & 800 & 399.7 & 398.1 & 0.9 \\
\hline 5 & 2000 & 392.1 & 388.1 & 0.9 \\
\hline 6 & 1700 & 387.4 & 384.8 & 0.8 \\
\hline 7 & 1600 & 383.8 & 380.3 & 0.8 \\
\hline 8 & 1700 & 379.0 & 376.1 & 0.8 \\
\hline
\end{tabular}

It is based on the lateral canal WM within the Maricopa Stanfield Irrigation and Drainage District in central Arizona, with a length of $9.5 \mathrm{~km}$, and is divided into eight pools by a series of controllable orifices gates. These gates are vertical sluice gates, and in canal 1, they are assumed to be always unsubmerged. Besides, these gates are motorized, enabling the control of the system. The maximum value allowed for gate movement is restrictive to the $0.5 \%$ of gate height, and it can be modeled with whatever suitable equations for the simulation software. The canal drops $40 \mathrm{~m}$ in elevation; thus, the beginnings of all pools are distributed by different descending heights, inducing the water gravity movement. Some gravity offtakes are also included and located $5 \mathrm{~m}$ from the downstream end of each pool (it has no flow at the downstream end).

The resulting PI controller parameters for the three tuning rules considered are presented in Table 2.

Table 2. Proportional and Integral parameters of proportional-integral (PI) controllers based on the linear matrix inequality (LMI) Method.

\begin{tabular}{ccccccc}
\hline \multirow{2}{*}{ No. Pool } & \multicolumn{2}{c}{ LMI Method 1 } & \multicolumn{2}{c}{ LMI Method 2 } & \multicolumn{2}{c}{ LMI Method 3 } \\
\cline { 2 - 7 } & $\boldsymbol{K}_{p}$ & $\boldsymbol{K}_{\boldsymbol{i}}$ & $\boldsymbol{K}_{\boldsymbol{p}}$ & $\boldsymbol{K}_{\boldsymbol{i}}$ & $\boldsymbol{K}_{\boldsymbol{p}}$ & $\boldsymbol{K}_{\boldsymbol{i}}$ \\
\hline 1 & 1.3079 & 0.0383 & 1.1542 & 0.0334 & 1.4104 & 0.0428 \\
\hline 2 & 2.5170 & 0.0718 & 2.6483 & 0.0826 & 2.5172 & 0.0727 \\
\hline 3 & 2.1069 & 0.0631 & 2.1260 & 0.0653 & 2.1411 & 0.0659 \\
\hline 4 & 5.9515 & 0.1676 & 5.8530 & 0.1635 & 6.1181 & 0.1715 \\
\hline 5 & 6.8866 & 0.1956 & 6.8934 & 0.1961 & 6.8971 & 0.1939 \\
\hline 6 & 8.5417 & 0.2418 & 8.5433 & 0.2410 & 8.5357 & 0.2331 \\
\hline 7 & 5.3328 & 0.1619 & 5.3329 & 0.1620 & 5.3329 & 0.1621 \\
\hline
\end{tabular}

\subsubsection{Simulation Settings}

The system starts from a steady-state as the initial condition of the tests, where the first gate is not controlled and is opened at $0.5 \mathrm{~m}$ above the crest level, and the setpoints for canals 2 to 8 are 19.3, 16.5, $16.1,14.5,10.4,6.8$ and $3.8 \mathrm{~m}$, respectively. The simulation length is $12 \mathrm{~h}$, and the control time step is $5 \mathrm{~min}$. The input flow is set at $1 \mathrm{~m}^{3} / \mathrm{s}$ during the first $4 \mathrm{~h}$, when a step of input flow is produced by increasing it up to $1.2 \mathrm{~m}^{3} / \mathrm{s}$ for the rest of the test (from hour 4 to 12). The offtakes at the end of each 
pool are set to $0.1 \mathrm{~m}^{3} / \mathrm{s}$ throughout the test. The total number of simulations performed is seven, one for each method analyzed under the same conditions.

\section{Results}

The results obtained from the simulation performed in the software of Sobek are presented in Figure 2 for the three LMI methods, and in Figure 3 for the four PIF methods [51]. All of them represent the water level errors, $X(\mathrm{~m})$, depicted at each time sample $\left(T_{\mathrm{s}}=4 \mathrm{~min}\right)$. The key performance indicators (KPIs) defined are reported for all methods in Tables 3-5, with the best value of each indicator highlighted in bold font.

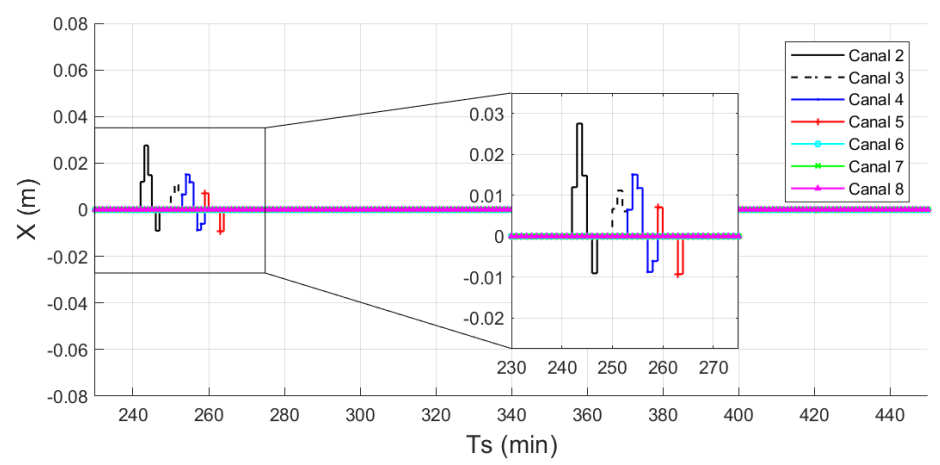

(a)

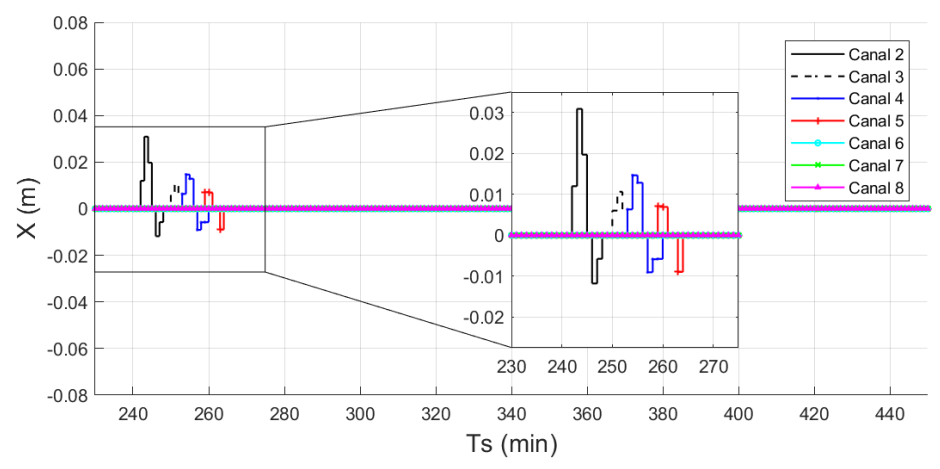

(b)

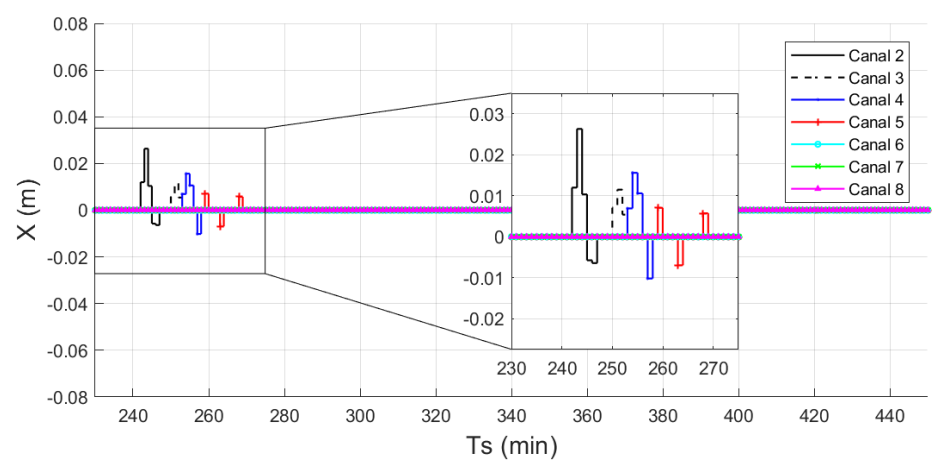

(c)

Figure 2. Simulation results for step change of $0.2 \mathrm{~m}^{3} / \mathrm{s}$ in the non-lineal canal model for the LMI methods (described in Section 2.2.2): (a) $Q$ tuning approach 1 of LMI method; (b) $Q$ tuning approach 2 of LMI method; (c) $Q$ tuning approach 3 of LMI method. 


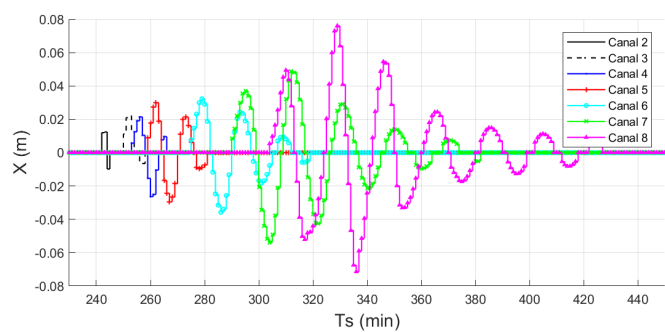

(a)

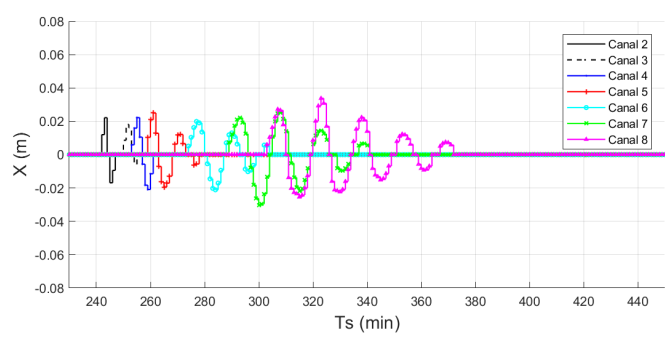

(c)

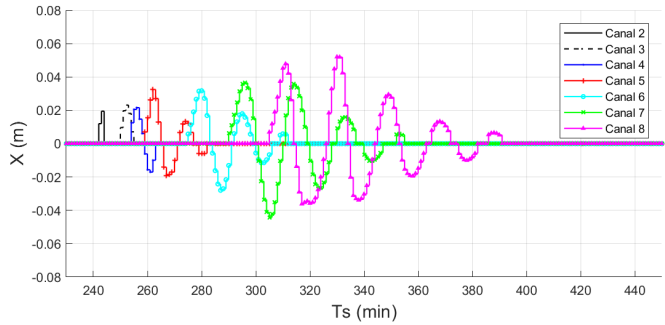

(b)

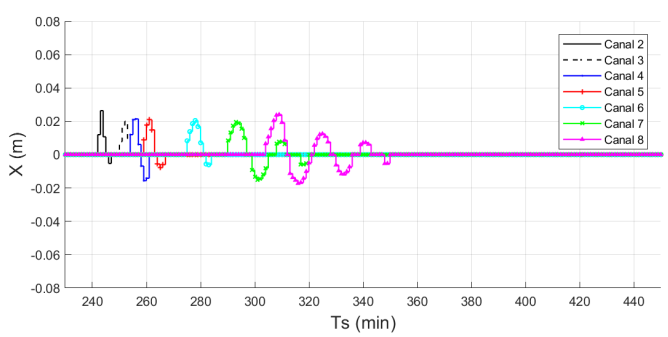

(d)

Figure 3. Simulation results for step change of $0.2 \mathrm{~m}^{3} / \mathrm{s}$ in the non-lineal canal model for the proportional-integral filtered (PIF) methods [51]: (a) Method 1 of PIF method; (b) Method 2 of PIF method; (c) Method 3 of PIF method; (d) Method 4 of PIF method.

Table 3. Non-linear model simulation key performance indicators (KPIs): maximum absolute error (MAE), integral of absolute magnitude of error (IAE), mean of mean absolute error (MMAE), mean of standard deviations (MSTD), and sum of standard deviations (SSTD).

\begin{tabular}{|c|c|c|c|c|c|c|c|}
\hline \multirow{2}{*}{ Methods } & \multicolumn{2}{|c|}{ MAE $\left(10^{-2}\right)$} & \multicolumn{2}{|c|}{$\operatorname{IAE}\left(10^{1}\right)$} & \multirow{2}{*}{$\begin{array}{c}\text { MMAE } \\
\left(10^{-3}\right)\end{array}$} & \multirow{2}{*}{$\begin{array}{l}\text { MSTD } \\
\left(10^{-2}\right)\end{array}$} & \multirow{2}{*}{$\begin{array}{l}\text { SSTD } \\
\left(10^{-2}\right)\end{array}$} \\
\hline & $\operatorname{Max}$ & Mean & Max & Mean & & & \\
\hline LMI Method 1 & 2.76 & 0.90 & 0.38 & 0.13 & 0.15 & 0.31 & 2.20 \\
\hline LMI Method 2 & 3.09 & 0.93 & 0.48 & 0.16 & 0.18 & 0.35 & 2.42 \\
\hline LMI Method 3 & 2.63 & 0.86 & 0.37 & 0.13 & 0.15 & 0.30 & 2.12 \\
\hline PIF Method 1 & 7.60 & 3.67 & 15.04 & 4.51 & 5.21 & 3.14 & 21.96 \\
\hline PIF Method 2 & 5.21 & 3.21 & 9.22 & 3.03 & 3.51 & 2.43 & 17.02 \\
\hline PIF Method 3 & 3.38 & 2.47 & 5.21 & 1.85 & 2.14 & 1.69 & 11.83 \\
\hline PIF Method 4 & 2.64 & 2.18 & 2.31 & 0.85 & 0.98 & 1.12 & 7.85 \\
\hline
\end{tabular}

Table 4. Non-linear model simulation KPIs: Resilience.

\begin{tabular}{lcccccccc}
\hline \multicolumn{1}{c}{ RESILIENCE $\left(\mathbf{1 0}^{-\mathbf{1}}\right)$} \\
\hline Methods & Canal 1 & Canal 2 & Canal 3 & Canal 4 & Canal 5 & Canal 6 & Canal 7 & Mean \\
\hline LMI Method 1 & 3.33 & 3.33 & 3.33 & 10.00 & 0.01 & 0.01 & 0.01 & $\mathbf{2 . 8 6}$ \\
\hline LMI Method 2 & 3.33 & 3.33 & 3.33 & 5.00 & 0.01 & 0.01 & 0.01 & 2.15 \\
\hline LMI Method 3 & 2.00 & 3.33 & 3.33 & 10.00 & 0.01 & 0.01 & 0.01 & 2.67 \\
\hline PIF Method 1 & 3.33 & 2.50 & 2.00 & 2.00 & 1.43 & 1.11 & 1.11 & 1.93 \\
\hline PIF Method 2 & 5.00 & 2.00 & 1.11 & 1.67 & 1.25 & 1.00 & 1.11 & 1.88 \\
\hline PIF Method 3 & 5.00 & 3.33 & 1.25 & 1.11 & 1.67 & 1.43 & 1.43 & 2.17 \\
\hline PIF Method 4 & 3.33 & 2.50 & 1.43 & 2.50 & 1.67 & 1.43 & 1.25 & 2.02 \\
\hline
\end{tabular}


Table 5. Non-linear model simulation KPIs: Vulnerability.

\begin{tabular}{lcccccccc}
\hline \multicolumn{1}{c}{ VULNERABILITY $\left(\mathbf{1 0}^{-\mathbf{2}}\right)$} \\
\hline Methods & Canal 1 & Canal 2 & Canal 3 & Canal 4 & Canal 5 & Canal 6 & Canal 7 & Mean \\
\hline LMI Method 1 & 2.76 & 1.12 & 1.51 & 0.93 & 0.00 & 0.00 & 0.00 & 0.90 \\
\hline LMI Method 2 & 3.09 & 1.06 & 1.47 & 0.90 & 0.00 & 0.00 & 0.00 & 0.93 \\
\hline LMI Method 3 & 2.63 & 1.15 & 1.56 & 0.71 & 0.00 & 0.00 & 0.00 & $\mathbf{0 . 8 6}$ \\
\hline PIF Method 1 & 1.24 & 2.21 & 2.64 & 3.00 & 3.58 & 5.39 & 7.60 & 3.67 \\
\hline PIF Method 2 & 1.95 & 2.31 & 2.16 & 3.25 & 3.17 & 4.43 & 5.21 & 3.21 \\
\hline PIF Method 3 & 2.22 & 1.81 & 2.22 & 2.50 & 2.11 & 3.05 & 3.38 & 2.47 \\
\hline PIF Method 4 & 2.64 & 2.00 & 2.14 & 2.10 & 2.05 & 1.96 & 2.40 & 2.18 \\
\hline
\end{tabular}

Many different key performance indicators (KPIs) can be calculated from simulation results to facilitate the comparison between all the methods considered; thus, just a selection of them has been chosen for this study. First, two performance indicators recommended to used for canal control analysis in [44] are selected: the maximum absolute error (MAE) and the integral of absolute magnitude of error (IAE). Their defining expressions are [44]:

$$
\begin{aligned}
& \text { MAE }=\frac{\max \left(\left|y_{t}-y_{\text {target }}\right|\right)}{y_{\text {target }}} \\
& \text { IAE }=\frac{\frac{\Delta t}{T} \sum_{t=0}^{T}\left|y_{t}-y_{\text {target }}\right|}{y_{\text {target }}}
\end{aligned}
$$

where $y_{t}$ is the observed water level at time $t, y_{\text {target }}$ is the target water level, $\Delta t$ is the regulation time step, and $T$ is the time period for test. To minimize the total number of indicators presented and thus allowing an improvement of its understanding, it is enough reporting only the maximum and the average values of all pools for each indicator [44].

In addition, other performance indicators usually applied in many engineering studies are considered as well:

- The mean value of all the mean absolute water level error values of each pool, named as mean of mean absolute error (MMAE).

- The mean value of how dispersed the absolute water level error values are with respect to its mean value, named as mean of standard deviations (MSTD).

- The total sum value of how dispersed the absolute water level error values are with respect to its mean value, named as the sum of standard deviations (SSTD).

Lastly, regarding water resources management, there are also two other indicators commonly used to compare the performances of different water resource systems [54]. One is the resilience, which refers to how quickly a system is likely to recover from failure once it has occurred. The other is the vulnerability, which refers to the likely magnitude of a potential failure, defining it as the occurrence of unsatisfactory performance. Both are defined as the following expressions:

$$
\begin{gathered}
\varphi=\frac{f_{s}}{f_{d}}, \\
\eta=\frac{\sum_{j=1}^{f_{s}} \max \left(s_{j}\right)}{f_{s}},
\end{gathered}
$$

where $\varphi$ is the resilience and $\eta$ the vulnerability, $f_{s}$ is the number of individual continuous sequences of failure periods, $f_{d}$ is the total duration of all the failures and $s_{j}$ is the volumetric shortfall during $j$ th continuous failure sequence [55]. 
Finally, the KPIs used to assess the controllers appear as follows:

- MAE: Table 3.

- IAE: Table 3.

- MMAE: Table 3.

- MSTD: Table 3.

- $\quad$ SSTD: Table 3.

- Resilience: Table 4.

- Vulnerability: Table 5.

\section{Discussion}

The results show the better performance of LMI methods in comparison with the PIF ones. In particular, the following aspects can be analysed.

\subsection{Performance Indicators}

Regarding the water level error values, LMI methods reach smaller maximums. MAE values in Table 3 show that most PIF methods have higher values than those of LMI methods. Furthermore, the vulnerability values of Table 5 also support this claim.

Water level error fluctuations are almost negligible in LMI methods and decrease at downstream gates. By contrast, fluctuations in PIF methods are higher and have greater relevance in the last gates. All figures and IAE values (Table 3) stress this fact.

Also, the MMAE, MSTD, and SSTD values (Table 3) are all lower for LMI methods, meaning that these methods have a lower average of mean error values for all canals and there are fewer deviation from from the mean value.

Lastly, LMI methods are faster to achieve the setpoint once a disturbance has occurred. This can be seen by comparing all figures and numerically checked by the values of the resilience (Table 4), where the highest values belong to the LMI methods.

Therefore, PIF methods are outperformed by LMI methods. Also, considering only the set of the four PIF methods, our results confirm the analysis performed in [51]: PIF method 4 provides the best results. Indeed, some of its indicator performance values are relatively close to the ones of LMI.

\subsection{Tuning and Performance}

Finally, considering the three LMI methods and presenting them in decreasing order of performance, we can conclude that:

1. LMI Method 3 has the best performance, presenting the best values for all but one KPI. It has the second best value for the resilience (Table 4), i.e., its great performance is achieved by slightly sacrificing the total time required to recover. Its main characteristic is the lowest maximum value as shown in Figure 2, Table 3 (MAE and IAE), and Table 5 (vulnerability).

2. LMI Method 1 has the second best performance, presenting intermediate values in most KPIs. Some of them are very similar to the best values of LMI Method 3, as shown in Table 3. Moreover, the fastest response was observed in this method since it has the highest resilience value (Table 4).

3. LMI Method 2 has the worst performance of LMI methods, however it is sufficient when all methods are jointly considered as its KPI values are above average. In particular, its response is similar to the other two LMI methods, however the performance indicators are slightly worse.

In summary, the designed LMI methods outperform the PIF given in [51], with LMI method 3 being the best.

\subsection{Overall Assessment}

The results obtained are not surprising since the proposed method recasts the PI tuning problem as an optimal control problem where a sparse linear feedback is calculated to steer the irrigation canal 
optimally according to a given cost function. For this reason, the tuning calculated by the LMI is closer to the optimal feedback, which is the well-known LQR. This can be seen by using the suboptimality indicator $\eta$ presented in [56], which is defined as

$$
\eta=\frac{\operatorname{trace}\left(P_{\mathrm{PI}}\right)}{\operatorname{trace}\left(P_{\mathrm{LQR}}\right)}
$$

thus measuring the ratio between the expected cost-to-go of the LQR and the corresponding PI feedback. Here, $P_{\mathrm{LQR}}$ corresponds to the infinite horizon solution of the associated discrete-time Riccati equation, which corresponds to (8); likewise, $P_{\mathrm{PI}}$ is computed according to (8) for the considered equivalent PI feedback, say $K_{\mathrm{PI}}$. This indicator satisfies $\eta \geq 1$ because no other linear feedback can outperform the LQR. The results corresponding to the best tuning found for each family of methods are $\eta_{\mathrm{LMI} 3}=2.82$ and $\eta_{\mathrm{PIF} 4}=4.01$, i.e., the proposed tuning is less suboptimal than the PIF one, improving the optimality degree of the PI tuning by $30 \%$. This result is general and the superiority of the proposed approach with respect to other PI methods will hold as long as they are not calculated considering the cost-to-go of the closed-loop system.

\section{Conclusions}

A new PI design method for irrigation canals has been presented in this study. Linear Matrix Inequalities are applied for tuning the PI parameters based on the cost function of an optimal control problem. The design method has been tested by simulations in SOBEK using the ASCE Test Canal 1 and compared with the methods of [51].

Another advantageous possibility of the design method is self-tuning. As we have shown, the weights considered in the objective function can be successfully set based on the canal model parameters.

PI parameters generate a map between functions of the error and control actions. For this reason, it is not straight forward to link their values to that of cost-related performance indicators. In the procedure presented here, only the weight of the error in the cost-to-go of the closed-loop system has to be tuned. After that, the LMI generates the error-input mapping, by tuning the PI parameters taking into account the system performance.

Likewise, some of the PI design issues can be overcome by casting the problem as an LMI, e.g., different operating points and uncertainties. Indeed, the LMI framework is very versatile and the method presented here can also be easily extended to other controllers typically considered in irrigation canals, e.g., decouplers. Moreover, the controller design problem consists of the calculation of an optimal sparse feedback for the system. Hence, the resulting tuning can be linked to an optimal control problem like that of the well-known LQR. Actually, the computation procedure is that of the LQR within the LMI framework with fewer degrees of freedom derived from the necessary sparsity of the controller. As a consequence, any tuning computed with this method will have a higher degree of optimality than other PI tuning methods that do not account for the cost-to-go of the closed-loop system. Likewise, note that the proposed design method is centralized. Hence, synergies between local controllers are exploited and unwanted interactions between local PIs are minimized. Not surprisingly, all these features lead to superior performance, just as our simulations with SOBEK have shown, thus providing a useful tool for irrigation canal control.

Author Contributions: conceptualization, J.M.M. and G.G.; methodology, J.M.M.; software, T.A. and X.T.; validation, T.A. and X.T.; formal analysis, G.G.; resources, X.T.; writing-original draft preparation, T.A.; writing-review and editing, J.M.M. and X.T.; visualization, T.A. and X.T.; supervision, J.M.M. and G.G.; funding acquisition, J.M.M. All authors have read and agreed to the published version of the manuscript.

Funding: This research was funded by the European Research Council (Advanced Research Grant 769051-OCONTSOLAR) and the MINECO-Spain project DPI2017-86918-R.

Conflicts of Interest: The authors declare no conflict of interest. 


\section{References}

1. Gleick, P.H. Water use. Annu. Rev. Environ. Resour. 2003, 28, 275-314. [CrossRef]

2. Foley, J.A.; DeFries, R.; Asner, G.P.; Barford, C.; Bonan, G.; Carpenter, S.R.; Chapin, F.S.; Coe, M.T.; Daily, G.C.; Gibbs, H.K.; et al. Global consequences of land use. Science 2005, 309, 570-574. [CrossRef]

3. Döll, P.; Siebert, S. Global modeling of irrigation water requirements. Water Resour. Res. 2002, 38, 8-1-8-10. [CrossRef]

4. Wade, R.; Chambers, R. Managing the main system: Canal irrigation's blind spot. Econ. Political Wkly. 1980, 15, A107-A112.

5. Shahdany, S.M.H.; Firoozfar, A.; Maestre, J.; Mallakpour, I.; Taghvaeian, S.; Karimi, P. Operational performance improvements in irrigation canals to overcome groundwater overexploitation. Agric. Water Manag. 2018, 204, 234-246. [CrossRef]

6. Malaterre, P.O.; Rogers, D.C.; Schuurmans, J. Classification of canal control algorithms. J. Irrig. Drain. Eng. 1998, 124, 3-10. [CrossRef]

7. Burt, C.M. Regulation of Sloping Canals by Automatic Downstream Control. Ph.D. Thesis, Department of Agricultural and Irrigation Engineering, Utah State University, Logan, UT, USA, 1982; p. 172.

8. Burt, C.M. Irrigation District Canal Automation-CARDD; ASAE Publication: Phoenix, AZ, USA; 1990, pp. 495-500.

9. Chevereau, G.; Schwartz-Benezeth, S. BIVAL system for downstream control. In Planning, Operation, Rehabilitation and Automation of Irrigation Water Delivery Systems; ASCE: Preston, VA, USA, 1987; pp. 155-163.

10. Shahverdi, K.; Monem, M.J. Construction and evaluation of the bival automatic control system for irrigation canals in a laboratory flume. Irrig. Drain. 2012, 61, 201-207. [CrossRef]

11. Negenborn, R.R.; van Overloop, P.J.; Keviczky, T.; De Schutter, B. Distributed model predictive control of irrigation canals. NHM 2009, 4, 359-380. [CrossRef]

12. Fele, F.; Maestre, J.M.; Hashemy, S.M.; de la Peña, D.M.; Camacho, E.F. Coalitional model predictive control of an irrigation canal. J. Process Control 2014, 24, 314-325. [CrossRef]

13. Akouz, K.; Benhammou, A.; Malaterre, P.; Dahhou, B.; Roux, G. Predictive control applied to ASCE canal 2. In Proceedings of the 1998 IEEE International Conference on Systems, Man, and Cybernetics (Cat. No. 98CH36218), SMC'98, San Diego, CA, USA, 14 October 1998; Volume 4, pp. 3920-3924.

14. Hashemy, S.; Monem, M.; Maestre, J.; Van Overloop, P. Application of an in-line storage strategy to improve the operational performance of main irrigation canals using model predictive control. J. Irrig. Drain. Eng. 2013, 139, 635-644. [CrossRef]

15. Malaterre, P.O.; Rodellar, J. Multivariable predictive control of irrigation canals. Design and evaluation on a 2-pool model. In Proceedings of the International Workshop on Regulation of Irrigation Canals, Marrakech, Morocco, 22-24 April 1997; pp. 230-238.

16. Shahdany, S.H.; Maestre, J.; Van Overloop, P. Equitable water distribution in main irrigation canals with constrained water supply. Water Resour. Manag. 2015, 29, 3315-3328. [CrossRef]

17. Shahdany, S.H.; Taghvaeian, S.; Maestre, J.; Firoozfar, A. Developing a centralized automatic control system to increase flexibility of water delivery within predictable and unpredictable irrigation water demands. Comput. Electron. Agric. 2019, 163, 104862. [CrossRef]

18. Tian, X.; Guo, Y.; Negenborn, R.R.; Wei, L.; Lin, N.M.; Maestre, J.M. Multi-Scenario Model Predictive Control Based on Genetic Algorithms for Level Regulation of Open Water Systems under Ensemble Forecasts. Water Resour. Manag. 2019, 33, 3025-3040. [CrossRef]

19. Clemmens, A.; Replogle, J. Control of irrigation canal networks. J. Irrig. Drain. Eng. 1989, 115, 96-110. [CrossRef]

20. Wahlin, B.T.; Clemmens, A.J. Performance of historic downstream canal control algorithms on ASCE test canal 1. J. Irrig. Drain. Eng. 2002, 128, 365-375. [CrossRef]

21. Zamani, S.; Parvaresh Rizi, A.; Isapoor, S. The effect of design parameters of an irrigation canal on tuning of coefficients and performance of a PI controller. Irrig. Drain. 2015, 64, 519-534. [CrossRef]

22. Burt, C.M.; Mills, R.; Khalsa, R.D. Improved proportional-integral (PI) logic for canal automation. J. Irrig. Drain. Eng. 1998, 124, 53-57. [CrossRef]

23. van Overloop, P.J.; Schuurmans, J.; Brouwer, R.; Burt, C.M. Multiple-model optimization of proportional integral controllers on canals. J. Irrig. Drain. Eng. 2005, 131, 190-196. [CrossRef] 
24. van Overloop, P.J.; Weijs, S.; Dijkstra, S. Multiple model predictive control on a drainage canal system. Control Eng. Pract. 2008, 16, 531-540. [CrossRef]

25. Karanjkar, D.; Chatterji, S.; Kumar, A. Development of linear quadratic regulator based PI controller for maximum power point tracking in solar photo-voltaic system. In Proceedings of the 2014 Recent Advances in Engineering and Computational Sciences (RAECS), Chandigarh, India, 6-8 March 2014; pp. 1-6.

26. Litrico, X.; Malaterre, P.O.; Baume, J.P.; Vion, P.Y.; Ribot-Bruno, J. Automatic tuning of PI controllers for an irrigation canal pool. J. Irrig. Drain. Eng. 2007, 133, 27-37. [CrossRef]

27. Lan, D.C. Research on Canal System Automation Control Based on Adaptive Parameters Fuzzy. In Applied Mechanics and Materials; Trans Tech Publications Ltd.: Stafa-Zurich, Switzerland, 2013; Volume 373, pp. 1529-1532.

28. Litrico, X.; Fromion, V.; Baume, J.P.; Rijo, M. Modelling and PI control of an irrigation canal. In Proceedings of the 2003 European Control Conference (ECC), Seville, Spain, 3-5 April 2003; pp. 850-855.

29. Baume, J.P.; Malaterre, P.O.; Sau, J. Tuning of PI controllers for an irrigation canal using optimization tools. In Proceedings of the USCID Workshop on Modernization of Irrigation Water Delivery Systems, Phoenix, AZ, USA, 17-21 October 1999.

30. Lozano, D.; Arranja, C.; Rijo, M.; Mateos, L. Simulation of automatic control of an irrigation canal. Agric. Water Manag. 2010, 97, 91-100. [CrossRef]

31. Rijo, M.; Arranja, C. Supervision and water depth automatic control of an irrigation canal. J. Irrig. Drain. Eng. 2010, 136, 3-10. [CrossRef]

32. Isapoor, S.; Montazar, A.; Van Overloop, P.; Van De Giesen, N. Designing and evaluating control systems of the Dez main canal. Irrig. Drain. 2011, 60, 70-79. [CrossRef]

33. Litrico, X.; Fromion, V.; Baume, J.P. Tuning of robust distant downstream PI controllers for an irrigation canal pool. II: Implementation issues. J. Irrig. Drain. Eng. 2006, 132, 369-379. [CrossRef]

34. Aguilar, J.V.; Langarita, P.; Linares, L.; Rodellar, J. Automatic control of flows and levels in an irrigation canal. IEEE Trans. Ind. Appl. 2009, 45, 2198-2208. [CrossRef]

35. Alamo, T.; Normey-Rico, J.E.; Arahal, M.; Limon, D.; Camacho, E. Introducing linear matrix inequalities in a control course. IFAC Proc. Vol. 2006, 39, 205-210. [CrossRef]

36. Martins, V.D.S.; Rodrigues, M. A proportional integral feedback for open channels control trough LMI design. IFAC Proc. Vol. 2011, 44, 4107-4112. [CrossRef]

37. Clemmens, A.; Wahlin, B. Simple optimal downstream feedback canal controllers: ASCE test case results. J. Irrig. Drain. Eng. 2004, 130, 35-46. [CrossRef]

38. Lian, F.; Chakrabortty, A.; Duel-Hallen, A. Game-Theoretic Multi-Agent Control and Network Cost Allocation under Communication Constraints. IEEE J. Sel. Areas Commun. 2017, 35, 330-340. [CrossRef]

39. Lin, F.; Fardad, M.; Jovanovic, M.R. Design of Optimal Sparse Feedback Gains via the Alternating Direction Method of Multipliers. IEEE Trans. Autom. Control 2013, 58, 2426-2431. [CrossRef]

40. Rotkowitz, M.; Lall, S. Decentralized Control Information Structures Preserved Under Feedback. In Proceedings of the 41th IEEE Conf. on Decision and Control, Las Vegas, NV, USA, 10-13 December 2002.

41. Maestre, J. Distributed Model Predictive Control Based on Game Theory. Ph.D. Thesis, The University of Seville, Andalucia, Spain, 2010.

42. Maestre, J.M.; Muñoz de la Peña, D.; Jimenez Losada, A.; Algaba, E.; Camacho, E.F. A coalitional control scheme with applications to cooperative game theory. Optim. Control Appl. Methods 2013, 35, 592-608. [CrossRef]

43. Polyak, B.T.; Khlebnikov, M.V.; Shcherbakov, P. An LMI approach to structured sparse feedback design in linear control systems. In Proceedings of the 2013 European Control Conference (ECC), Zurich, Switzerland, 17-19 July 2013.

44. Clemmens, A.; Kacerek, T.; Grawitz, B.; Schuurmans, W. Test cases for canal control algorithms. J. Irrig. Drain. Eng. 1998, 124, 23-30. [CrossRef]

45. Wahlin, B.T. Performance of model predictive control on ASCE test canal 1. J. Irrig. Drain. Eng. 2004, 130, 227-238. [CrossRef]

46. Clemmens, A.; Sloan, G.; Schuurmans, J. Canal-control needs: Example. J. Irrig. Drain. Eng. 1994, 120, 1067-1085. [CrossRef]

47. Schuurmans, J.; Bosgra, O.; Brouwer, R. Open-channel flow model approximation for controller design. Appl. Math. Model. 1995, 19, 525-530. [CrossRef] 
48. Schuurmans, J.; Hof, A.; Dijkstra, S.; Bosgra, O.; Brouwer, R. Simple water level controller for irrigation and drainage canals. J. Irrig. Drain. Eng. 1999, 125, 189-195. [CrossRef]

49. Clemmens, A.; Schuurmans, J. Simple optimal downstream feedback canal controllers: Theory. J. Irrig. Drain. Eng. 2004, 130, 26-34. [CrossRef]

50. Ghainet, P.; Nemirovski, A.; Laub, A.; Chilali, M. LMI Control Toolbox-for Use with Matlab; The Math Works Inc.: Natick, MA, USA, 1995.

51. Clemmens, A.; Tian, X.; van Overloop, P.J.; Litrico, X. Integrator delay zero model for design of upstream water-level controllers. J. Irrig. Drain. Eng. 2015, 143, B4015001. [CrossRef]

52. Clemmens, A.; Bautista, E.; Wahlin, B.; Strand, R. Simulation of automatic canal control systems. J. Irrig. Drain. Eng. 2005, 131, 324-335. [CrossRef]

53. Liu, F.; Feyen, J.; Malaterre, P.O.; Baume, J.P.; Kosuth, P. Development and evaluation of canal automation algorithm CLIS. J. Irrig. Drain. Eng. 1998, 124, 40-46. [CrossRef]

54. Hashimoto, T.; Stedinger, J.R.; Loucks, D.P. Reliability, resiliency, and vulnerability criteria for water resource system performance evaluation. Water Resour. Res. 1982, 18, 14-20. [CrossRef]

55. McMahon, T.A.; Adeloye, A.J.; Zhou, S.L. Understanding performance measures of reservoirs. J. Hydrol. 2006, 324, 359-382. [CrossRef]

56. Muros, F.J.; Maestre, J.M.; Algaba, E.; Alamo, T.; Camacho, E.F. Networked control design for coalitional schemes using game-theoretic methods. Automatica 2017, 78, 320-332. [CrossRef]

(c) 2020 by the authors. Licensee MDPI, Basel, Switzerland. This article is an open access article distributed under the terms and conditions of the Creative Commons Attribution (CC BY) license (http:/ / creativecommons.org/licenses/by/4.0/). 